\title{
A REVIEW OF SYMBOLISM IN INDIGENOUS WEST AFRICAN TEXTILES
}

\author{
E. V. Ulzen-Appiah (Mrs) \\ Department of Industrial Art \\ Kwame Nkrumah University of Science and Technology, Kumasi, Ghana
}

\begin{abstract}
West African textiles form an important aspect of African art. Their uniqueness in the sense of symbolism reflects in their cultures and many forms of art and design. This paper traces some paths through the complex and still largely un-researched history of African textile artistry. It will explore some of the ways in which cloth has been and remains important in a selection of African societies, prominent among them West African textile art. It will introduce some of the major designs that have flourished in the $C 20$ th, those which are both cherished in their local context and increasingly sought after by collectors and museums world-wide. Finally, the picture will be brought up to date through a consileration of the role of cloth traditions in contemporary dress and fashion design.
\end{abstract}

Keywords: imagery, symbolism, motifs, textiles

\section{INTRODUCTION}

People often wonder about the fuss made for West African textiles. The main reason, to a great extent, is that the strength of a peoples' culture and greatness lies in their ability to keep alive in the dark secrecy of symbolism the cherished truths and values of life. This adage is exhibited strongly in West African textiles.

The artistry, aesthetic and tactile sophistication of West African textiles and dress has been admired and appreciated by foreign observers since the time of Greek and Roman contacts with Pharaohs of ancient Egypt. The Portuguese navigators who first explored the West African coast in the late $15^{\text {th }}$ century brought home finely embroidered raffia cloths from the Kongo tribe as prized examples of African textile design. Early in the $20^{\text {th }}$ century abstractly or ornamental raffia cloths from the Kuba kingdom in the interior of Zaire inspired artists such as Henri Matisse and Paul Klee (Price, 1976).

However, most of the $20^{\text {th }}$ century African textiles have been neglected even by enthusiasts of African art, and it is only very recently that overseas interest has grown and thus prompted to a large extent the re-discovery of African designs inspired by the Pan African ideology of the 1960's (Clarke, 1997).

These new diasporas have caused a blossoming interest in clothing styles that have developed out of ancestral traditions of the various cultures embracing the fashions of the contemporary world.

\section{DESIGN OF TEXTILES}

West African textile artists seem to favour a more improvised, fluid effect that plays with deliberate asymmetries and pattern variation. 
This trait has been compared with the emphasis on the off-beat in African music, notions of religions and society, goodness or virtue, disgrace or misdemeanour, death, manners, time and colour and also basic ideals of beauty, ideals of kings courts, duty and personalitics of society, beauty in the manner of doing things, the art of poetry, expressed art in the form of mythology, art of symbolic objects used in adorning state regalia and royal gold weights. Many designs are also named after perceived visual similarities like the crocodile's back.

In the early days, any one who could produce a design that was recognised as new was highly regarded. Today the main ceremonial occasions and court rituals for which indigenous West African textiles are produced are not regular events in the market. Many of them have been replaced by modern mechanised printed or woven textiles.

\section{SYMBOLISM OF CLOTH}

Another dimension of the social significance of cloth in many West African societies provides a stark contrast to the abstract economic role, as money, and social role, as body covering.

Textiles, worn regularly next to the skin whether for everyday use, or in particular ritual contexts, take on something of the personal identity of the wearer as they absorb the secretions of the body. This close tie between the textiles and their owners is a symbolic extension of the day-to-day reality of cloth use, and makes them powerful metaphorical ingredient in a variety of magi coreligious practices. For instance, Yoruba herbalists would burn small pieces of hand woven cloth as an ingredient of amulets, while they felt were particularly appropriate for curing barren women or those troubled by persistent miscarriages. It is likely these remedies drew symbolic force from the significance of the cloth mothers used to carry their babies securely on their back. (Clarke, 1997). Contemporarily, the patterns are located in towns, regions or ethnic groups in various countries. Thesc localised patterns of stylistic development make them unique and have apparently contradictory impacts on issues of personal and group identity. On one hand, it contributes to the development of notions of localized group identity, on the other hand it forms a long-distance trade.

\section{WOVEN TEXTILES}

Traditional textiles are generally woven on narrow traditional looms. Usually two forms of weaving technology overlap and both the upright single-heddle loom and the narrow strip double heddle loom are found in many countries, (Fig. 1a).

\section{Kente}

The village of Bonwire in Ghana is the traditional home of Kente. In the past the cotton and rayon textiles were strictly woven for the Asantehene (King of the Ashanti nation) and the royal house. Today, selected designs still remain the privilege of the kings but generally it is a fashion product. It is predominantly a geometric woven piece with bright coloured rayon and cotton yarns sometimes interspersed with black.

The various abstract designs have highly symbolic names dubbed after important personalities, social events and proverbial sayings. Its possession is a symbol of status and wealth in the society, (Fig. $1 \mathrm{~b}$ and $1 \mathrm{c}$ ).

\section{Kete, Adanudo and Smock Fabric}

The Ewes of the Volta region in Ghana are also famous for a type of woven cotton textiles similar to Kente and referred to as Kete, (Fig. 2). Another type of woven piece named Adanudo has motifs inserted in the weave structure, (Fig. 3). The motifs have highly symbolic names - for cxample, a comb refers to a woman's beauty.

The inhabitants of northern Ghana weave a simple striped fabric with limited colours for their traditional smock, (Fig. 4). The limited dark colours of the smock are enhanced by a brightly coloured cap worn with it for the performance of the ethnic Damba dance of the Dagombas. The blend of colours as portrayed in the circular mo- 

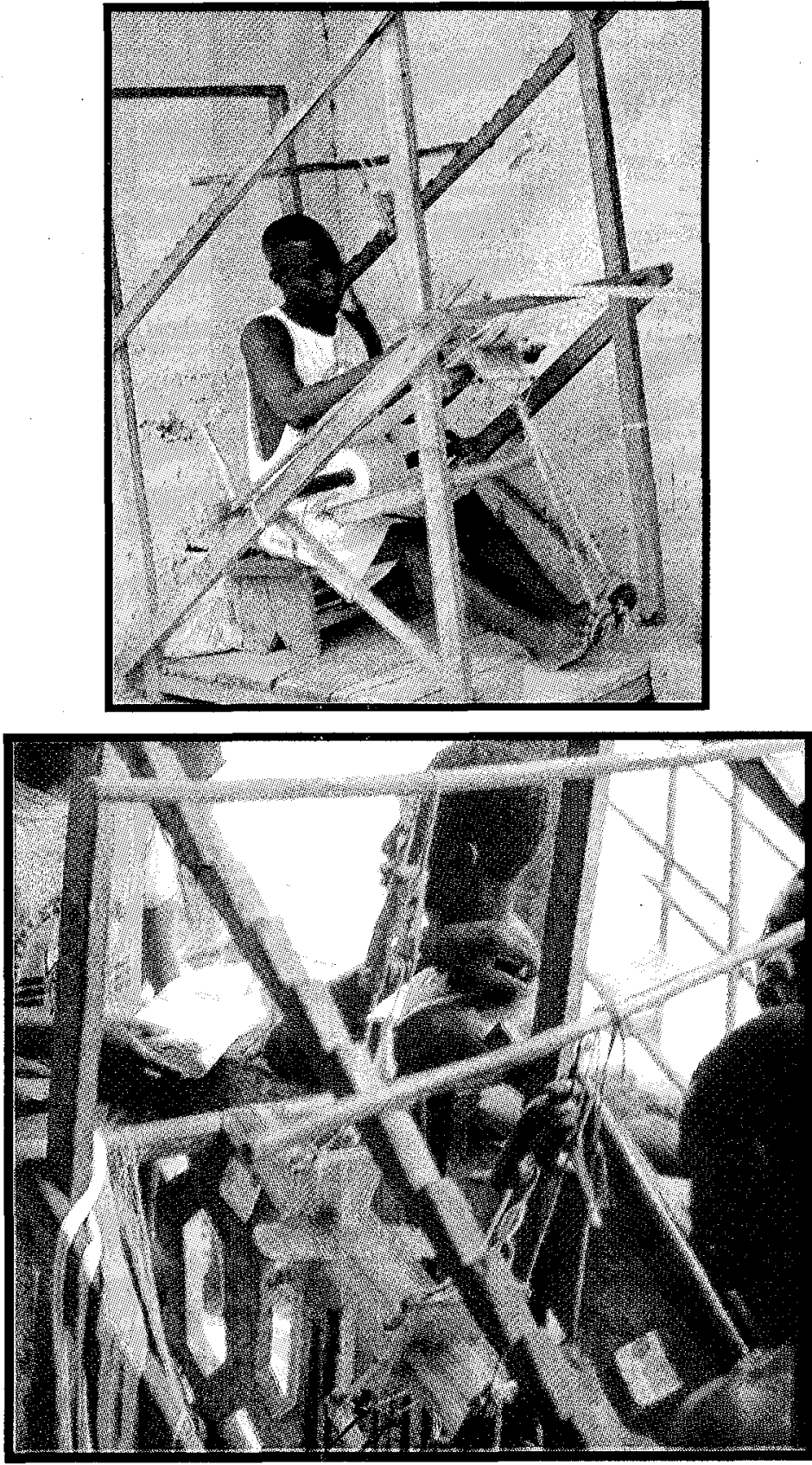

Fig. 1a: Woven Textiles - Traditional looms 


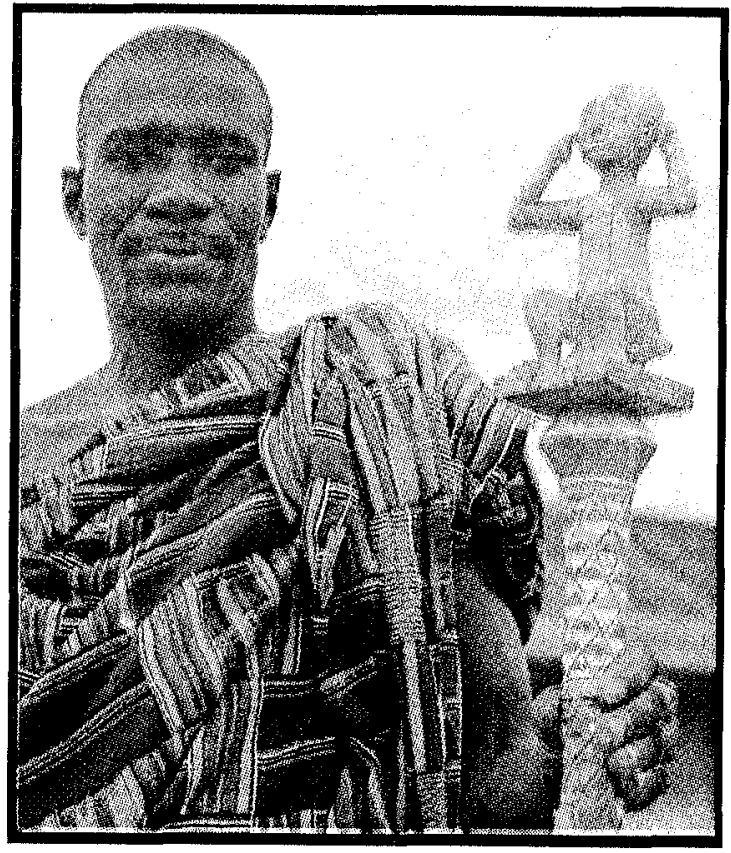

Fig. Ib: Kente - Ashanti, Ghana

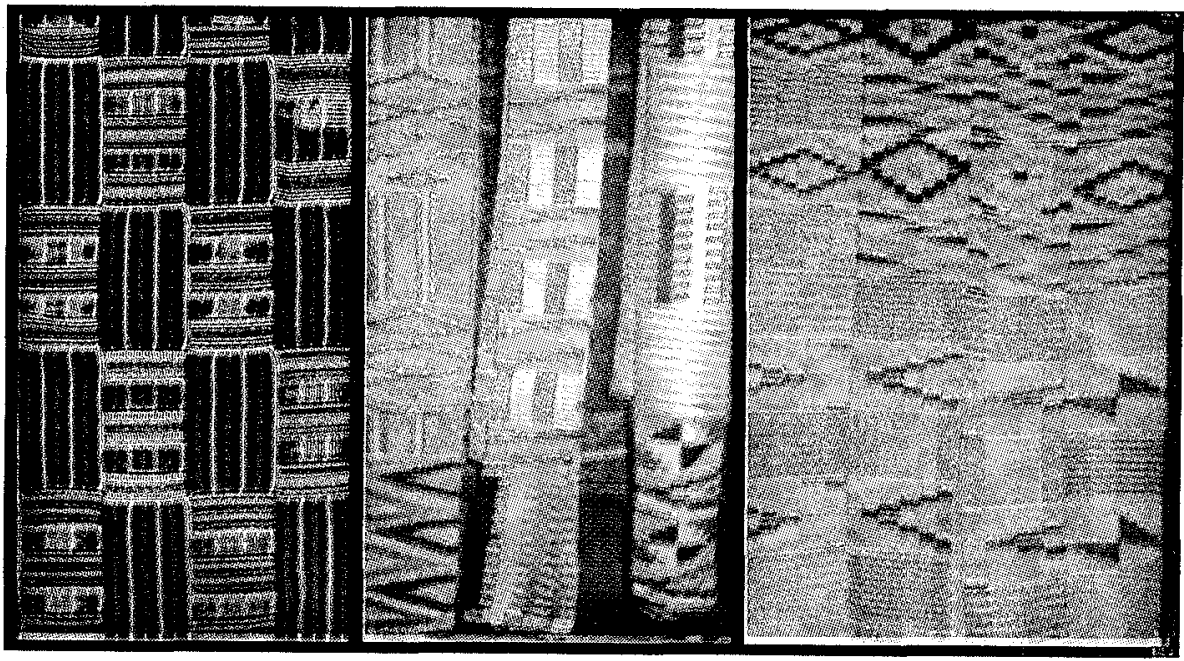

Fig. 1c: Kente-Ashanti, Ghana 


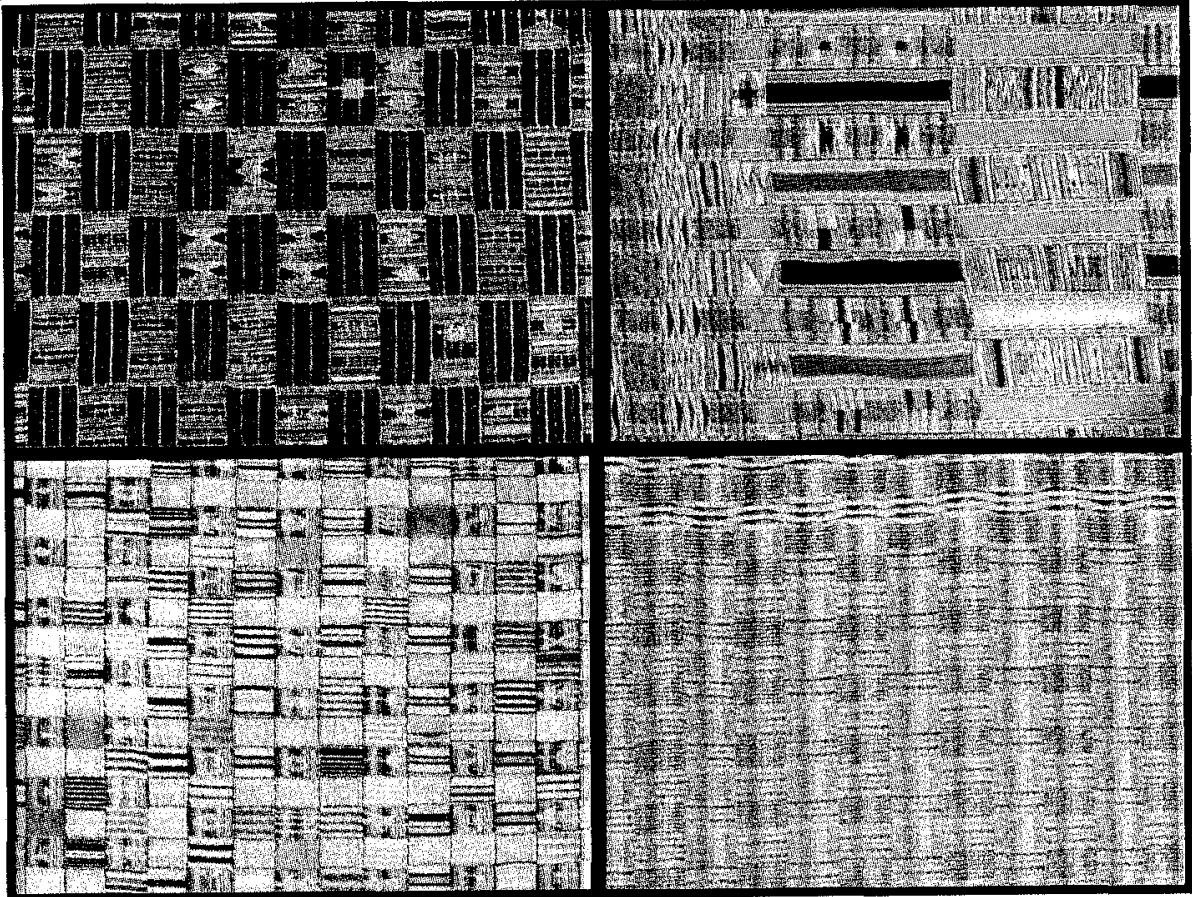

Fig. 2: Woven Textiles - Kete - Ewe, Ghana

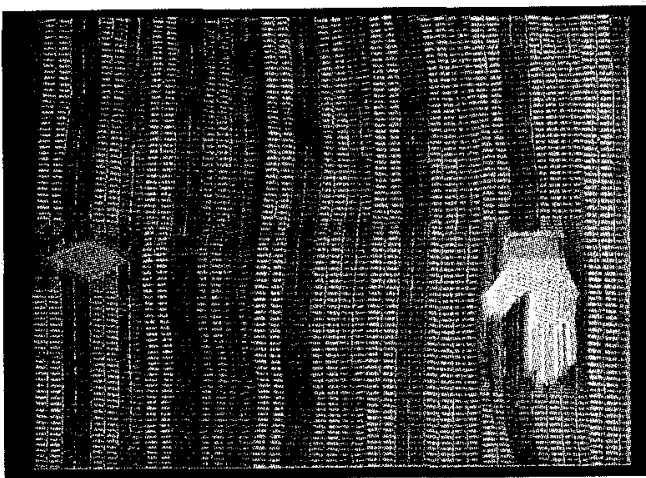

Fig. 3: Woven Textiles - Adanudo - Ewe, Ghana

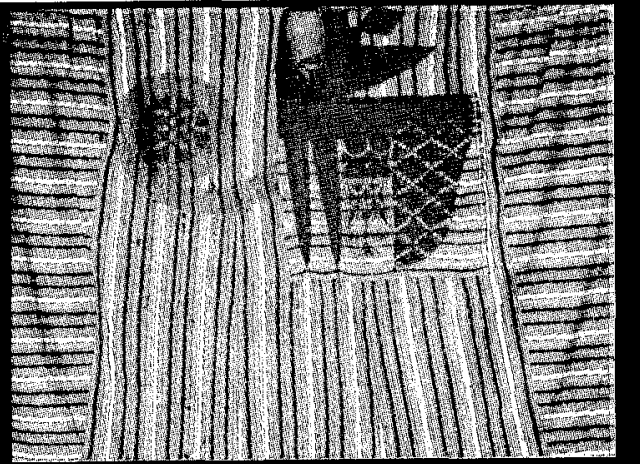

Fig. 4: Woven Textiles - Smock Cloth

- Dagomba, Ghana,

- Yoruba, Nigeria 


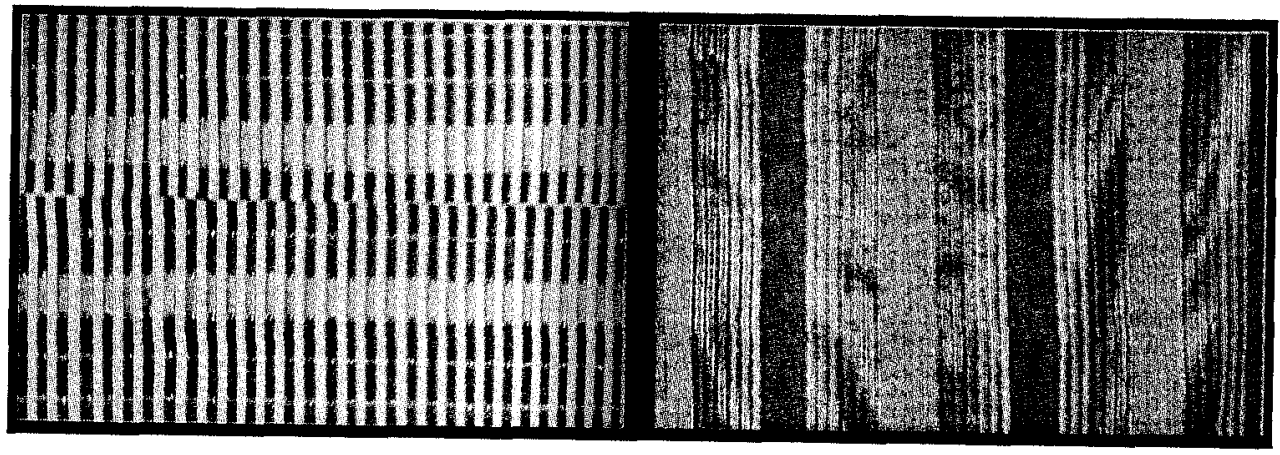

Fig. 5a

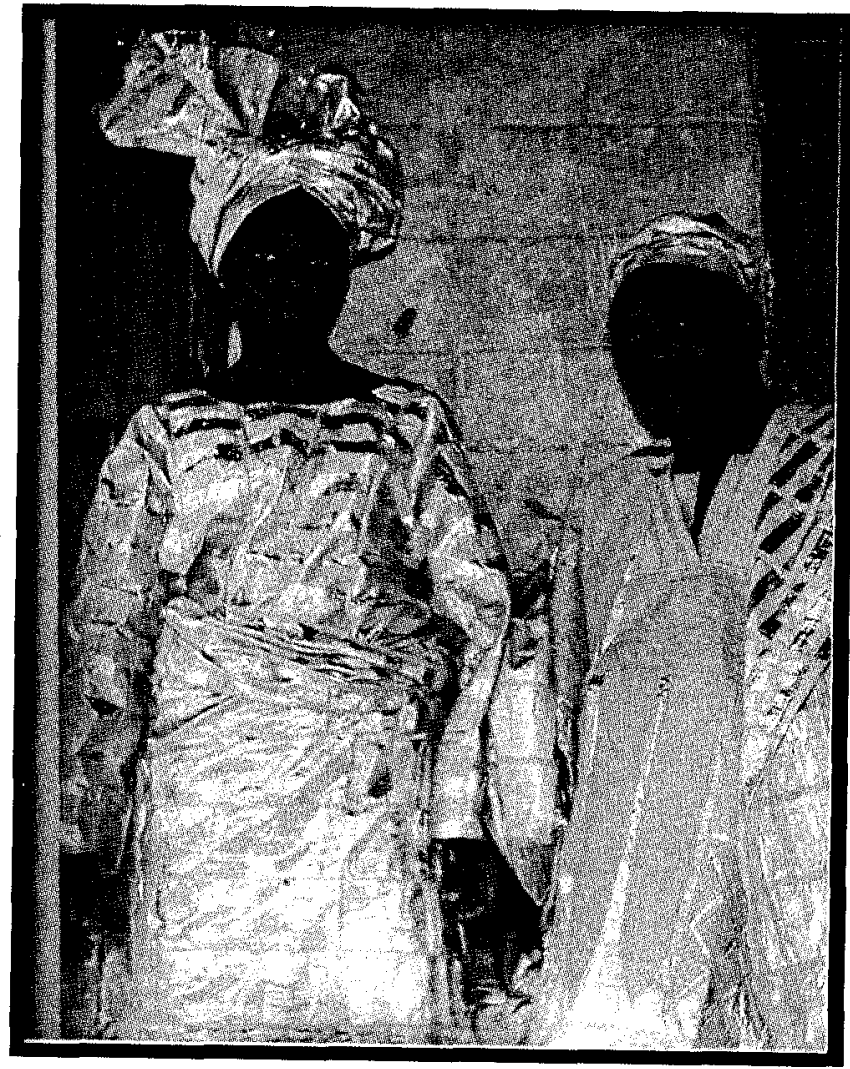

Fig. $5 b$

Fig. 5: Woven Textiles - Aso - Oke - Yomba, Nigeria 

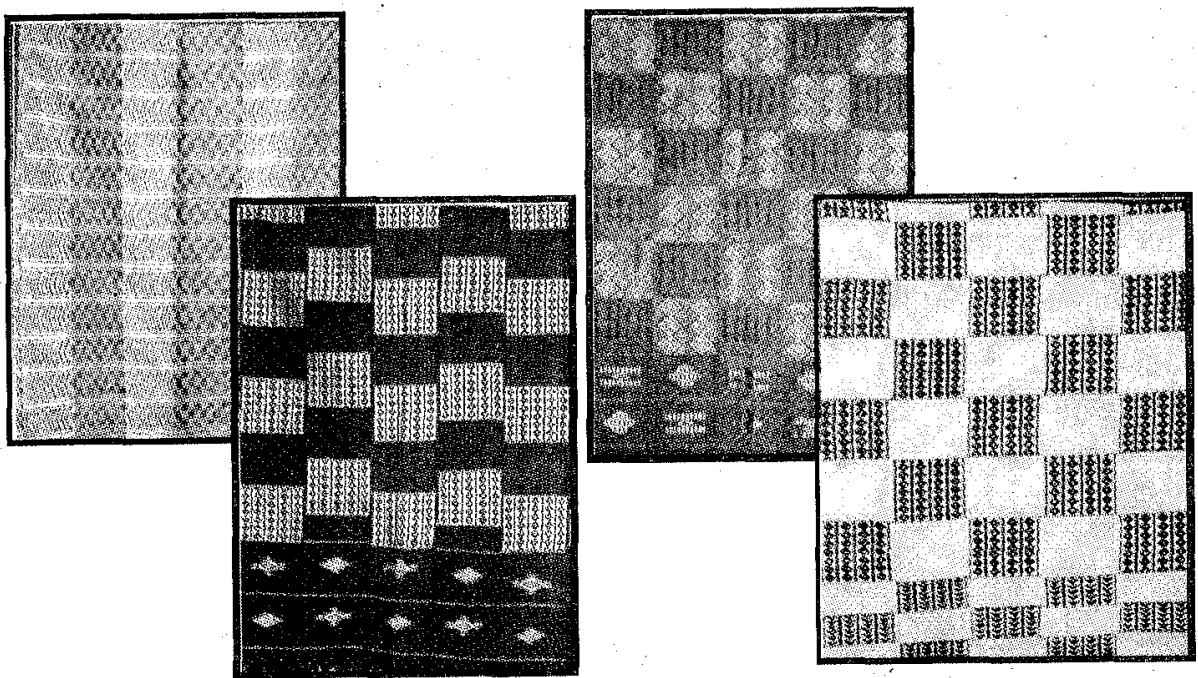

Fig. $5 c$

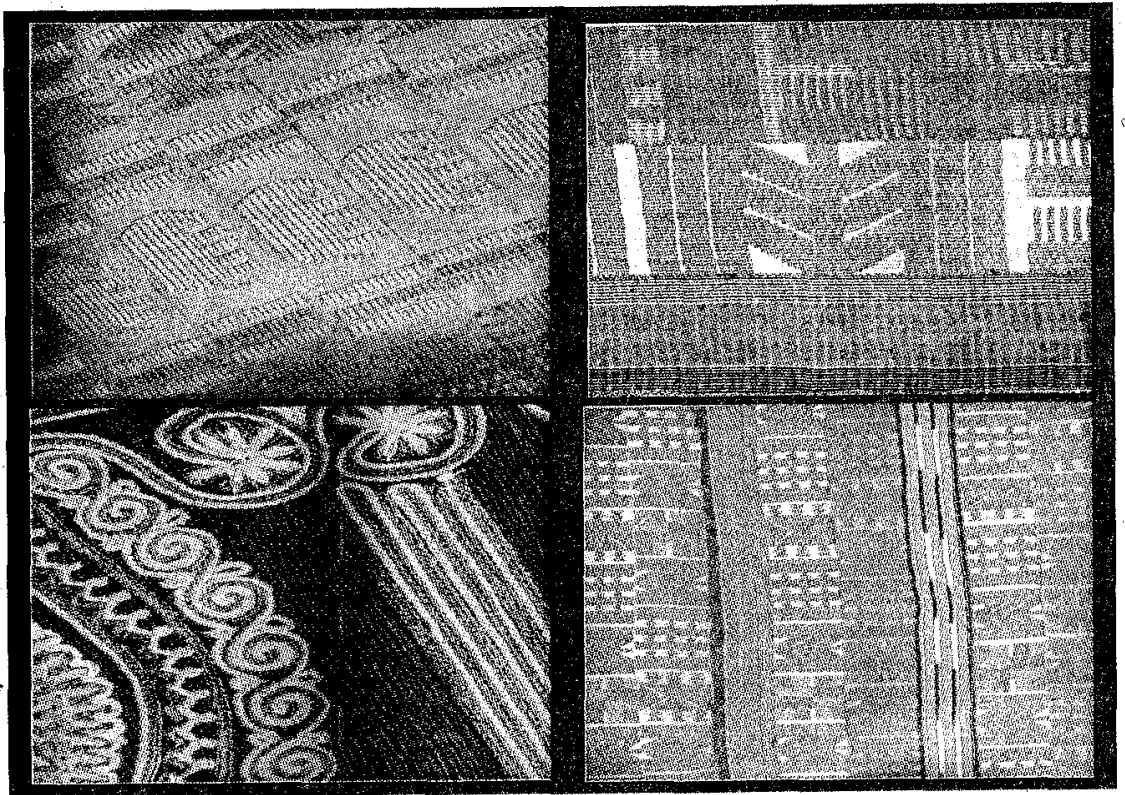

Fig. $5 d$ 


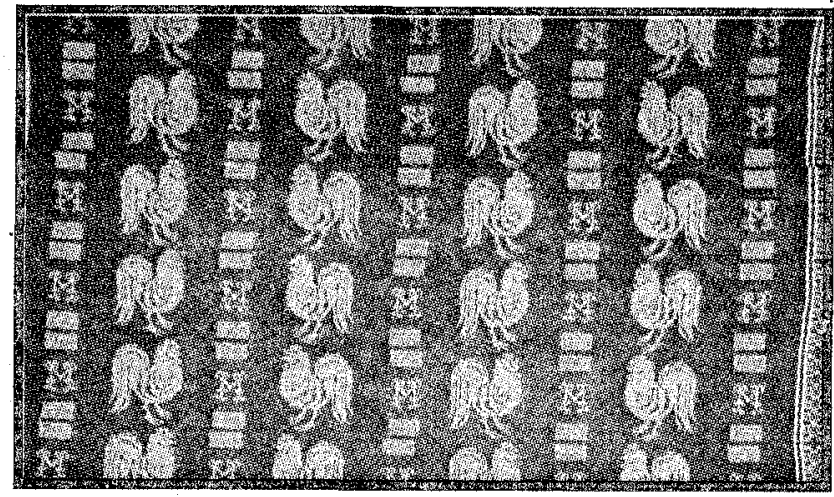

Fig. 6: Woven Textiles: Senegalese Bridal Cloth
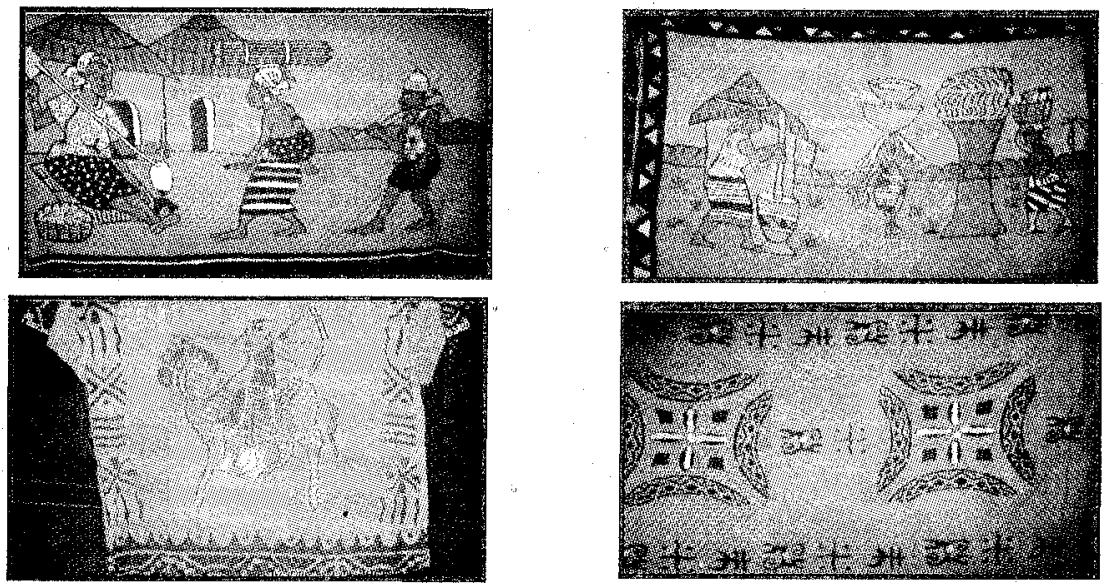

Fig. 7: Dyed Pieces - Bogolan Mud Cloth - Mali

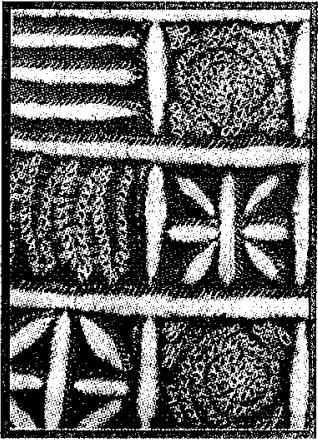

Fig. 8: Dyed Pieces - Adire Ibadan, Nigeria
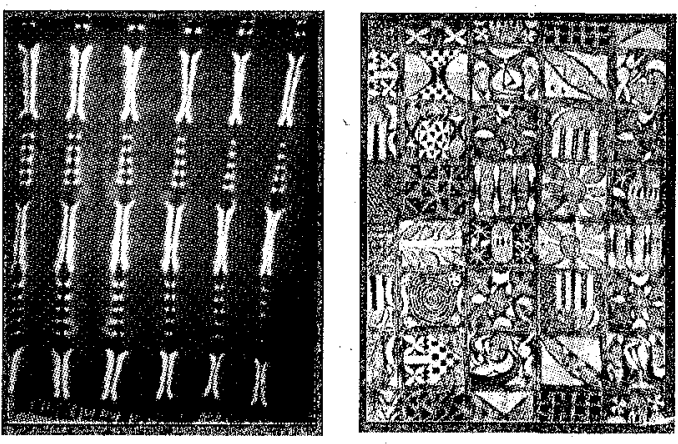

Fig. 9: Dyed Pieces - Adire Ibadan, Nigeria 
tion of the dance is a splendid rhythm of colour. (Ulzen-Appiah, E.V. 1998)

\section{Aso-Oke}

This is the ceremonial cloth of the Yorubas of Nigeria. There are three types. The Etu is deep blue and white with thin stripes, (Fig. 5a). The Samyan is beige in colour and formerly woven from silk, (Fig. 5b). The Alaari was formerly woven from magenta waste silk. Today, all three types are woven with cotton warp and rayon weft. Since the $19^{\text {th }}$ century, large quantities of waste silk from France and Italy have been shipped to Kano in Northern Nigeria and it has popularised the industry. It was a prestigious textile worn by the ruling Fulani aristocracy at the start of the $19^{\text {th }}$ century. Currently, it is a fashion fabric for both sexes, very popular in Nigeria and gradually developing in the Ghanaian market, (Fig. 5c and 5d). The Yoruba bridal woven cloth which is part of marriage dowry is a unique symbolic piece of this type. (Clarke, 1997).

Other woven pieces of cloth from Nigeria are of abstract designs and produced by the Yoruba, Fulani and Nupe weavers. In Nigeria, unlike Ghana, women are also weavers. The Fulanis of the inland Niger delta of Mali, parts of the Sudan kingdom, Liberia, Sierra Leone and Senegal are also noted for traditional weaving

A typical example is the Senegalese bridal cloth mostly woven by the Tukolor or Serer weavers. This is presented to a woman by her mother-inlaw on the occasion of the birth of her first child, (Fig. 6). This was used by the inhabitants of the whole of Dakar and other cities. The common ones seen today are of machine spun yarns. (Price, C.1976).

\section{DYED PIECES}

\section{Bogolan Mud Cloth Of Mali}

If Kente has long been regarded as a prominent African textile, its status has recently been challenged from an unexpected quarter. Over the last ten years the perception of Bogolan mud cloth has been transformed from a despised rural cloth associated with non-Islamic peasants to a symbol of national identity. While international, its new influence embraces both Parisian interior designs and as Afrocentric dress in the United States of America (Clarke, 1997).

Bogolanfini or Bogolan, is a cloth decorated by women in the Bamona speaking region of Mali, using a unique procedure that utilises dyes made from mud and leaves to produce white designs outline on a black background. (Fig. 7). It is a popular craft in the Malian capital - Bamako. In its local context it remains a crucial garment worn to mark important life cycle stages including birth, female circumcision, marriage and death (Clarke, 1997).

Internationally, a Paris-based Malian fashion designer, Bogose, has achieved widespread recognition by incorporating Bogolan in his clothes, starting a vogue for the distinctive designs which are now also being reproduced from New York to India (Feldman, 1992)

\section{Indigo Dyed Cloth Of Yoruba - Nigeria}

These are unique dyed textiles of indigo on white background. Varied patterns have symbolic names. For example, cross shaped patterns in the centre of spirals that look like a string of beads, mean 'welcome to the masquerade'. (Fig. 8). (Price, C.1976)

\section{Adire Fabrics}

These are resist dyed predominantly blue and white cloths with patterns painted on by either freehand or using metal stencil. A feather or rib of palm leaf serves as a brush and the resist paint is a mixture of alum and cassava starch, (Fig. 9).

Different combinations of designs give each cloth its name. For example, some names are 'all birds are here', and' we enjoy Ibadan'. Ibadan is the centre of the craft. (Price, C. 1976). 

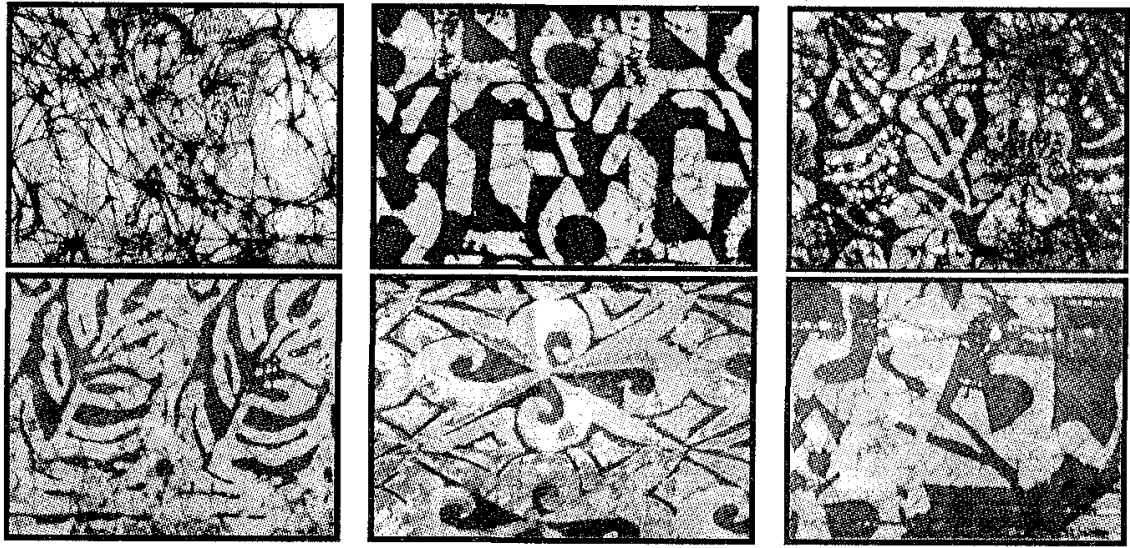

Fig. 10a: Dyed Pieces: Batik \& Tie, Ghana
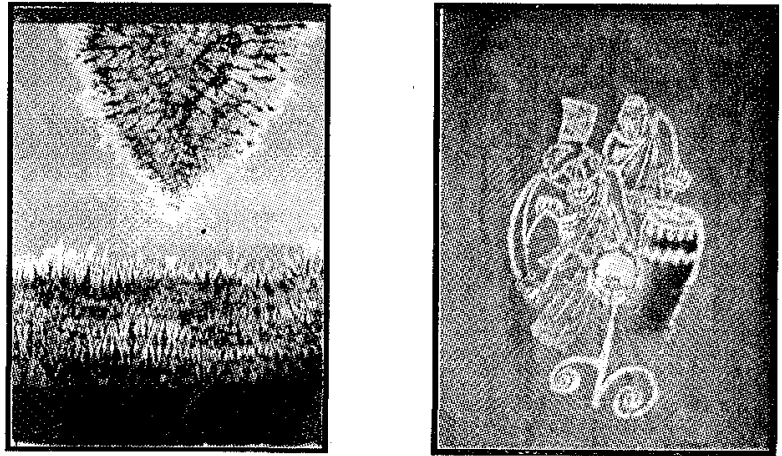

Fig. 10b: Dyed Pieces: Batik \& Tie, Ghana
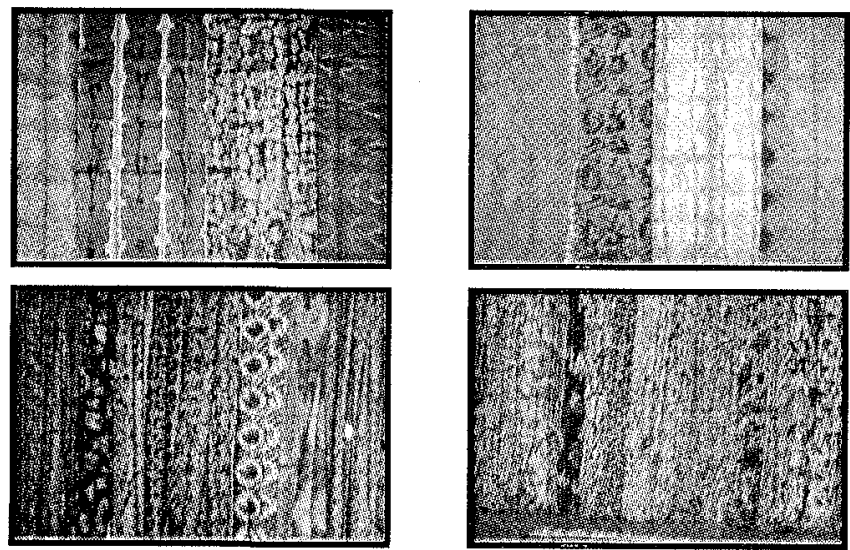

Fig. 10c: Dyed Pieces: Batik \& Tie, Ghana 


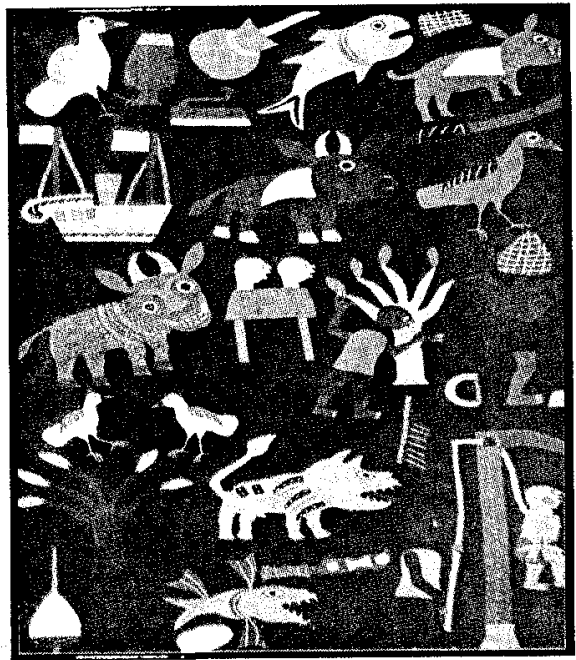

Fig. 11: Embroidered and Applique: Applique Pieces - Dahomey

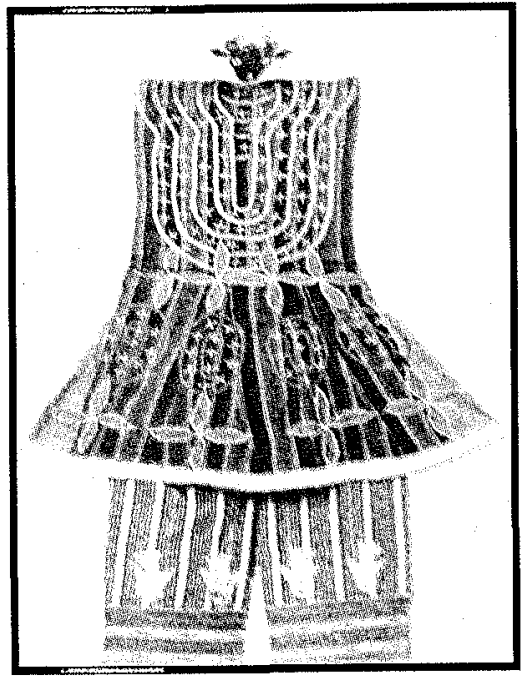

Fig. 13: Embroidered and Applique: Fulani Patterned Fabrics-Nigeria
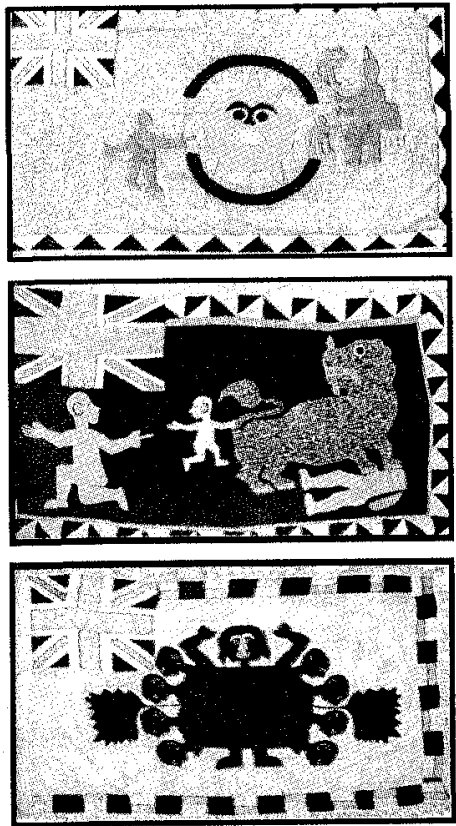

Fig. 12: Embroidered and Applique: Clan Cloth of Ghana
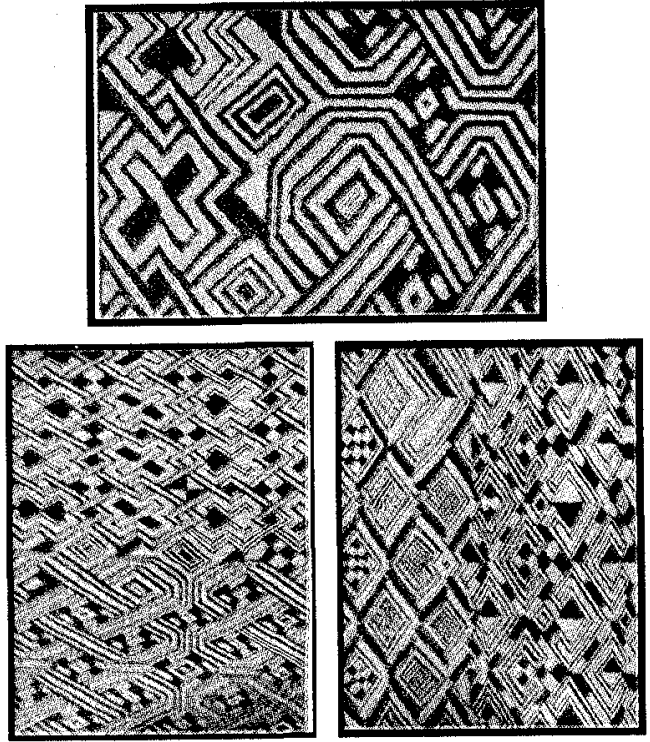

Fig. 14: Embroidered and Applique: Raffia Cloth - Zaire 


\section{Batik And Tie-Dyed Fabrics}

These are popular textile fabrics which exist in many West African countries such as Ghana, Nigeria, Liberia, Sierra Leone and Senegal, (Fig. 10a, b, c). It was originally an Indonesian art introduced on commercial basis along the west coast of Africa. Many individuals including the author have significantly developed this textile art in Ghana. Under the Ghana Ministry of Trade and Industry regional seminars on the African Growth Opportunity Act, the author has educated cntrepreneurs on the symbolic importance of these textile pieces

Non Governmental Organisations have assisted to train craftsmen in the area. It has become an up and coming thriving textile and clothing fashion business. In Ghana, the Ministry of Trade and Industry under the African Growth Opportunity Act (AGOA)also plans to train members of cluster groups to undertake training and produce the fabrics for export to the United States of America market (Ministry of Trade and Industry Report on AGOA( May, 2002).

\section{EMBROIDERED AND APPLIQUE FABRICS}

Embroidery is used to decorate clothes and fabrics in Ghana, Nigeria, Ivory Coast, Senegal and among the Fon people of Dahomey. Appliqué is also applied on clothing and some ceremonial textiles of the royalty, for example, state umbrellas, tents and banners. This is common among the royals of the Fantes, Ashantis and Ewes (Fig. 11). (Clarke, 1997)

In the $17^{\text {th }}$ century, Benhazin, the famous king of the Fon tribe of Dahomey had the shark embroidered on his costume - the shark being his insignia. Another king by name Agadja also had the ship as the symbol for appliqué cloth. Appliqué work in Dahomey was far more than a way of decorating textiles. It was an important royal art and the designs were told in pictures the history of the kingdom. (Clarke, 1997)

\section{Clan Cloth Of Ghana}

The clan groups of the Fantes of Ghana referred to as Asafo companies, also use appliqué ceremonial textiles. The designs on these flags are proverbial allusions that promote the sponsoring company, (Fig. 12) (Edusei, 2003).

\section{Fulani Patterned Pieces}

The Nupe craftsmen of the courts of the Fulani aristocracy of the Sokoto tribe of Northern Nigeria also produce another form of embroidered textiles. This probably dates from the early $20^{\text {th }}$ century. Embroidered abstract and proverbial symbols are made on smocks, caps, ladies kaftan and other dresses, (Fig. 13). It appears both on hand woven and printed fabrics. The art is also popular in Ghana, Liberia, Sierra Leone, Ivory Coast, Togoland and Senegal. (Price, 1976).

\section{Embroidered Raffia Cloths of Zaire}

These pieces are produced in the Kongo Kingdom of Western Zaire. They were greatly admired in the Renaissance period and entered the curio cabinets and treasures of kings and queens, (Fig. 14). Although Kongo raffia weaving died out in the face of competition from imported European cloth - elsewhere in Zaire, production of raffia cloth continued to this day. Contemporarily, it is used during funcrals of wealthy elders. (Clarke, 1997).

Patterns can be infused during weaving or $\mathrm{cm}$ broidered or appliquéd on plain fabric. Some are cut pile and some woven in square yards and bound together. The historian, Phyllis Martin, argues that these cloths formed a practical and versatile currency throughout the region. (Price, 1976)

\section{WEST AFRICAN HAND STAMPED, SCREEN, ROLLER AND WAX PRINTED TEXTILES \\ If the hand woven and decorated textiles de- scribed earlier represent the cultural heritage of the African past, the vibrant colours and flam- boyant designs of the wax stamped and machine printed cloths are more evocative of Africa to- day.}



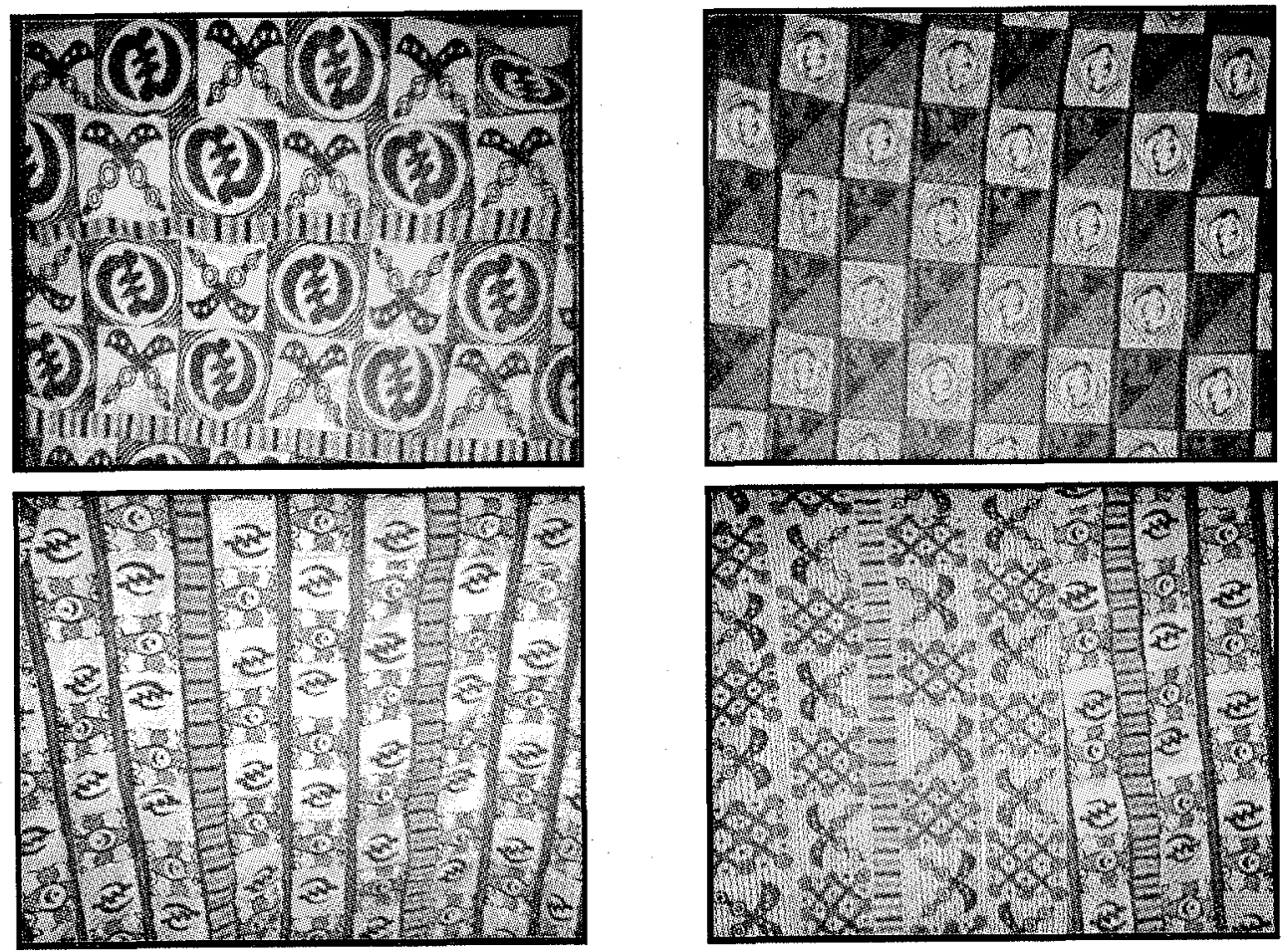

Fig. 15a: Printed Pieces: Adinkra - Stamp printed pieces - Ashanti, Ghana

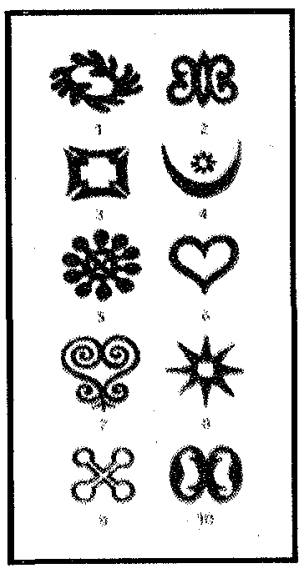

Fig. $15 b$

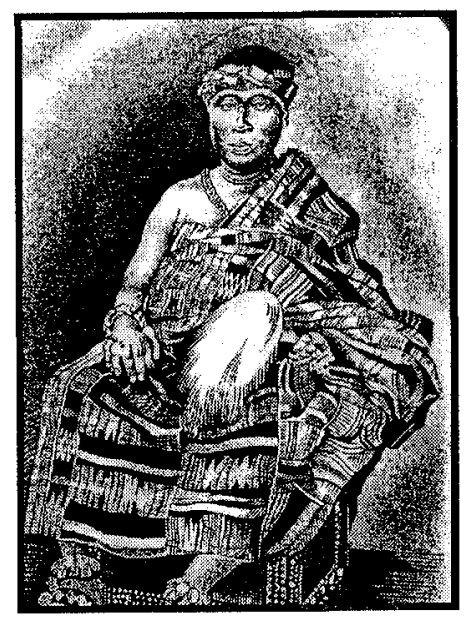

Fig. 16a: Screen and Roller Printed Pieces 


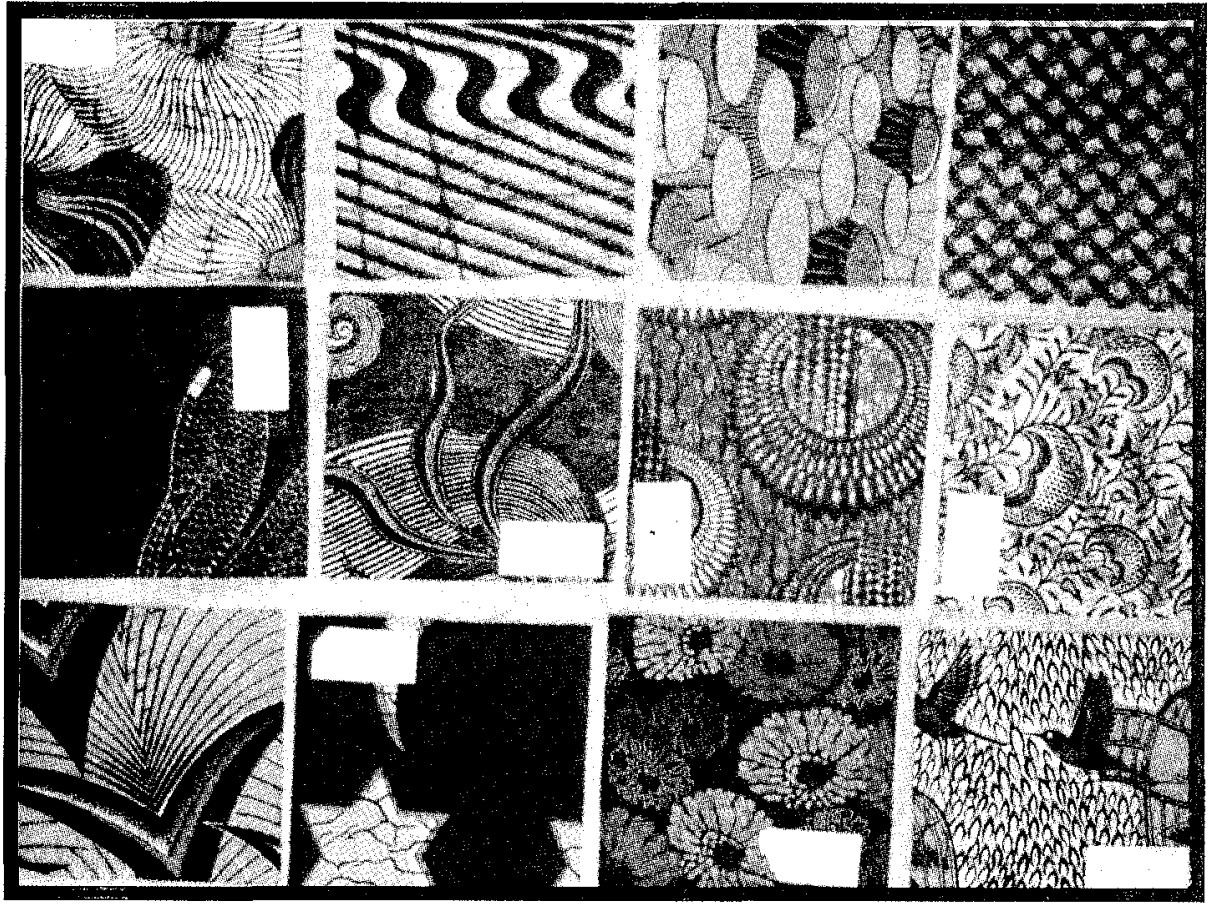

Fig. 16b: Screen and Roller Printed Pieces

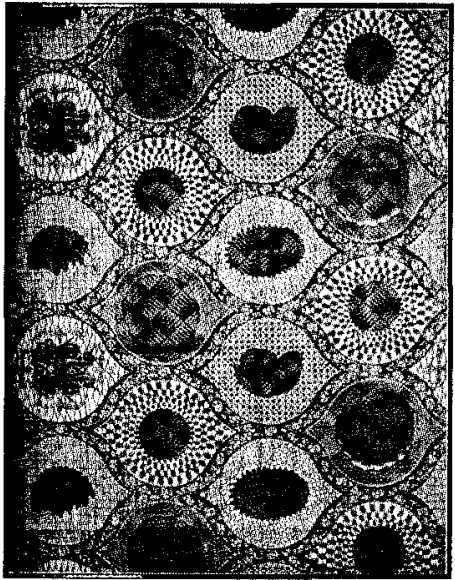

Fig. 16c:

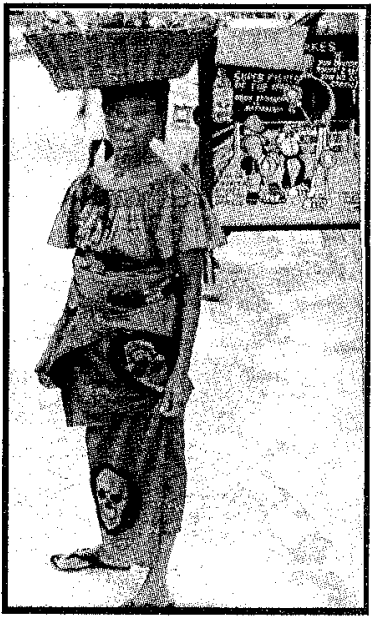

Fig. 16d:

Screen and Roller Printed Pieces 
The Adinkra stamped cloths of Ghana are also highly symbolic ceremonial textiles, (Fig. 15a and $b$ ). Wax printed cloths and cheaper screen and roller printed imitations have become one of the most widely distributed forms of African textiles today, produced and worn in almost every country in sub-Saharan Africa.

In the process they have become intricately entwined with the social and political life, despite their cxternal origin. Their complex history linking together Europi; Africa and Southern Asia has begun to be seriously investigated.

The symbolism attached to the naming of the designs has made it categorically African. Therefore, apart from its acsthetic interest, they have provided a new and versatile means of claborating long standing African interests in the communicative and expressive power of dress.

This involvement of European merchants in the cloth trade in Africa goes back many centuries. Although, these traders found Africa a ready market for almost all forms of textiles, they also rapidly discovered that African customers had clear and firmly expressed tastes and rejected any novel imports which did not satisfy their requirements in terms of quality and design. In line with this, the Manchester and Holland factories started producing these printed textiles for Africa. (Kroese, 1976). Today, it is gradually developing into giant textile industrial entities over West African countrics.

A major development is the introduction of the inferior quality known as fancy prints.

Some have varied subjective and objective designs with highly symbolic names and interpretations. These are designs that draw on the African interest in proverbs and mythology, for example, "one tree cannot stand the wind" and "death disintegrates family bonds."

Another category of designs is based on the influence of the Indonesian Batik designs such as complex floral and bird motifs. A third group dwells on the reproduction of local cmblems. A type with a cultural dimension is an imitation of the local hand woven kente or decorated textiles. Yet another group is based on commemorative cloths depicting kings, individuals, political figures and events. A good example is the commemorative cloth for King Prempeh I of Gold Coast in 1929. Fig. 16a. The last group comprises domestic items, (Fig. 16,b, c and d).

Scveral researchers have found that people, especially women, have been able to use the imagery and associated proverbs of some of these prints to send messages they would otherwise be unable to express publicly in society and in marriage circles.

Susan Domowitz noted that among the Anyi's of Ivory Coast and the Akans of Ghana the tensions underlying the apparent harmony of a polygamous houschold were expressed by cloths featuring circular designs. The design of such a cloth is said to mean that "co-wife rivalry is like cow-dung," a proverb that ends with "the top is dry but the inside is sticky." Another one bears the equally blunt title "condolences to my husband's mistress." (Price, 1975).

The basis for the naming of these prints are unimaginable.

The West African printed textile is far more than just a colourful and exotic mode of drcss. Its history is bound up with the complex interconnections fostered by the colonial involvement in Africa and the subsequent efforts of African nations to regain control over their economic destiny.

\section{DISCUSSION}

\section{Role of African Cloth}

After the $1^{\text {st }}$ World War, the intellectual interest of Western artists in West African cloth was followed by a seemingly superficial trend in society: The penctrating rhythms of the AfroAmerican jazz and dance music which was popular at the time made Africa a welcome source of inspiration for Western trends in art 
expression and movemient.

In the Spring of 1922, La Gazette du Bon Ton published the first six Western fashion textile prints inspired by ethnic African cloth and garment (Meij, 2002)

However, the African influence on cloth for fashion after the $1^{\text {st }}$ World War led to far more than perfunctory romantic or commercial adaptations. It followed, generally, in the wake of profound fascination on the part of Western artists such as Deran, Matisse and Picasso in the expressiveness of African masks, carvings and sculptured pieces.

The public fascination with Africa was also evident in the international trend setting magazine, VOGUE, immediately after the $1^{\text {st }}$ world war (Feldman, 1992).

African symbols such as lizards, snakes, tigers, crocodiles and zebras used in African textiles inspired textile designers such as Lean Zack and Raoul Dufy. Not only did animal symbols serve their needs but also other African cultures such as rivers and valleys of the sun drenched African landscape for their uniquely colourful designs. (Meij, 2002)

In 1997, Paris celebrated a multi-cultural African year marked by a profusion of music and exhibition featuring scarves, made with African patterns. Clothing designer Jessey Huyake, drew inspiration from African body paintings, tattoo and skin scarification's for textile designs.

Again, the African influence on cloth has left a distinctive mark on Western fashion, as can be seen from the spring/summer collection of clothes for 2001 by the Italian designer Giaufranco Ferre. (VOGUE Magazine, 2001).

For the Ghanaian elite, however, the genuine Vlisco wax print remains a coveted symbol of social prestige. Nigeria, Cote d'Ivoire, Togo, Liberia and Zaire also hold these West African symbolic textile prints in high esteem.
The question now is whether the symbolic product will continue to be the mainstay of West Africa, irrespective of quality and service? The market value of the product has been challenged by the infiltration of inferior quality ones from China and Europe.

Designers like Kofi Ansah and Joyce Ababio of Ghana have made concerted efforts to define another role for the West African symbolic wax print and other indigenous textiles from around Africa.They use such fabrics to produce casual wear, intriguing evening gowns and fascinating bridal wear.

The 'Woodin Concept', which envisages a chain of stylish cloth designs, is another strategy to expand the market.

West African indigenous textiles are seriously playing a significant role in contemporary market and in global cultural diffusion.

\section{CONCLUSION}

Without doubt the most elaborate account of the religious and symbolic significance of weaving in an African society was that provided by the Nigerian sage Ogotomeli to the celebrated and controversial French ethnographer Marcel Griaule. As part of the complex narrative is that which says that at each stage of local spinning and weaving, thread was a symbolic analogy to human reproduction and resurrection, that is "the making of cloth symbolises the multiplication of mankind." (Price, C.1976)

More common than this kind of extended cosmological analogy are myths that recount how the ancestors first learned to weave.

Two things are quite clear about West Africans and what the peoples of West African descent desire for their kind in the world today. No one can deny that they wish to see the west coast of Africa, their home and continent united and speaking with one voice. They also ardently desire to establish a respectable, distinctive identity for themselves; and this they have achieved in 
their textile and clothing arts. The arts reflect the culture and symbolism of the particular nations. For the future of the arts, the indicators are that perception and change will move with the changing times. The idea is more of a conglomeration and this is found in the indigenous textiles of West Africa.

\section{REFERENCES}

Antubam, Kofi (1963). Ghana's Heritage of Culture. Leipzig, Koehher and Amelang.

Clarke, Duncan (1997). The Art of African Textiles. London, Thunder Bay Press.

Edusei, Kodwo (2003). Asafo Flags of Ghana. Paper presented at the South Eastern College Arts Conference held at Raleigh, North Carolina, USA November.
Feldman, Elane (1992) Fashions of a Decade the 1990's. Hong Kong, World Print Limited.

Kroese, W.T (1976). The Origin of the Wax Block Prints on the Coast of West Africa, Netherlands, Duoprint bv

Meij, Letse (2002). Fashion and Ghana, Hague, Gemeentemuseu Ben Haag

Price, Christine (1975). Made In West Africa London, Macmillan Publishers .

Ulzen-Appiah, Esther Victoria (1998). Symbolism and Colour in Ghanaian Textiles. Unpublished Research Paper

VOGUE Magazine (2001). Dominant Features of the Seasons Collections London, Vol. 20, Number 2 . 